\title{
Picking a maintenance service: A user's view
}

\author{
DONALD I. TEPAS \\ Illinois Institute of Technology, Chicago, Illinois 60616
}

\begin{abstract}
A guide is provided for selecting small computer maintenance services. Types of available services are described, and a series of questions is answered concerning selection.
\end{abstract}

Although data processing equipment is becoming common in the psychology department, little systematic attention has been directed toward the problems associated with the maintenance of this equipment. Unlike cheap pocket calculators, laboratory computers still involve a significant capital investment of the sort that repair rather than replacement is required when a system breaks down. The anxiety of first ownership frequently leads purchasers to ignore maintenance issues as they concentrate on issues related to making the system do the required job. On the other hand, experienced owners may assume that manufacturer-based maintenance is the only option available, since this has been true in the past. One must also wonder how many potential laboratory computer users have rejected this technology simply because they assume that repair would be a major problem.

Many maintenance alternatives are now available to most small computer users. Both the naive and experienced user would do well to explore these various possibilities in an effort to seek out the most economical and satisfactory service. A sound approach by a department or institution with multiple systems can save thousands of dollars. When prompt repair is an issue, selecting the appropriate maintenance approach can save significant time. Maintenance is a tradition with computer equipment (unlike many forms of psychological research equipment), since most large computer systems in the past were leased rather than purchased. The lessor had to provide good maintenance to stay in business. With the advent of small systems, ownership became the rule, not leasing. Although the need for maintenance was recognized, few if any industry-wide standards were developed. Rapid technological advance, as well as the instability of many small computer manufacturers, makes it easy for one to own data processing equipment incorporating scarce components and very limited service options. Thus, the small computer user must show an interest in maintenance services if selfmaintenance is unacceptable.

The opinions expressed are those of the author and are not to be construed as necessarily reflecting the official view or endorsement of any manufacturer, supplier, or institution. The author wishes to thank numerous obscure administrators, vendors, and the U.S. government for their contribution to the knowledge he has gained in this area during 20 years of small computer use.
This paper reviews the various maintenance alternatives available to small computer users. Given the obvious assumption that different approaches to equipment maintenance are appropriate for various users, a number of questions are posed that each user should consider in selecting a maintenance service. Finally, the economics of paying for computer maintenance are discussed with special reference to the user in an academic environment.

\section{MAINTENANCE ALTERNATIVES AVAILABLE}

In practice, maintenance service can be performed by personnel from three possible sources: (1) personnel on the staff of the institution where the system is located, usually referred to as in-house or self-maintenance; (2) employees of the company who made the equipment, usually referred to as manufacturer-based maintenance; and (3) employees of a company that sells maintenance services but does not manufacture the equipment being serviced, usually referred to as thirdparty maintenance. Additional service options include where it is performed and the manner in which cost is determined. This result is a matrix of maintenance services, many of which are available to most users.

\section{In-House Maintenance by the User}

Diagnosis and repair by the user is probably attractive to only a small number of psychologist users. An individual desiring to be a repairman or an engineer probably never would have gone to graduate school in psychology in the first place. Attractive because it seems cheap, this can be the most costly approach, since you may do more harm than good. This is especially costly if you consider your own time to be worth money. Most computer scientists do not repair their manufactured equipment, so why should you?

\section{In-House Maintenance by a Specialist}

With small computers becoming more popular on campus, some institutions may employ a full-time specialist for the diagnosis and repair of equipment. This is probably economical only if the specialist services several or many systems within the institution. Theoretically, this can be economical, since it is possible that the specialist will know more about computers than you do. On the other hand, his resources, time, 
and experience may be quite limited. One attractive feature of this approach is that your system may be serviced by the same person every time. And the service person may become familiar with your specific problem. However, beware of the shop man who claims to have picked up computer service skills "on the side."

\section{Manufacturer-Based Maintenance Contract}

In this case, the user has a contract with the manufacturer to provide maintenance on a flat-fee basis. The fee usually includes the cost of parts and time. It may have some cost and time limits. In most cases a periodic preventive maintenance scheme, and rebuilding when needed, are included in the fee. The fee frequently varies with the range of hours per week you ask the service to be available on call. Although the fee is usually quoted on a monthly basis, yearly contracts are required. In most cases, this is the fastest service available. Similar to the traditional service provided to large computer installations, this is perhaps the safest route. It may also turn out to be the most uneven service, since some manufacturers have a shortage of good service people and a surplus of maintenance contracts. Don't be surprised if a different face shows up every time you have a service call.

\section{Manufacturer-Based Per-Call Service}

This is frequently referred to as hourly or per-call maintenance service since you pay by the hour for service. You also pay for parts in most cases. Expect the same staff to respond to per-call and contract requests, with contract requests being serviced first. If quick response is not an issue, per-call service can probably save you money if you have a time-proven system and are confident of a good service person. A difficult-todiagnose problem and/or a dull service person can cost you time and a fortune.

\section{Manufacturer-Based Depot Repair}

With this form of maintenance you diagnose the problem, and the manufacturer repairs the defective item at a distant repair depot to which you have forwarded the defective component, part, or unit. The manufacturer may aid with the diagnostic process. Some manufacturers will send you the required item without waiting for yours to arrive and be repaired. This, of course, can save time. However, in most cases you must wait for the item you sent to be repaired and returned. Unless you have a spare available, you are out of business until the item is returned and installed by you. This approach is only as good as your diagnostic skills. Fees are usually based on a time-plus-parts basis, but in some cases repair may involve a flat fee. This service is frequently promoted by small manufacturers with minimal regional maintenance capability. If the manufacturer goes out of business, you may be in serious trouble.

\section{Third-Party Maintenance Contract}

Identical in most respects to the manufacturerbased maintenance contract agreements, this is a maintenance contract serviced by a company whose main business is maintenance rather than manufacturing. In many geographical locations, a third-party maintenance contract is cheaper than the manufacturer-based contract. However, the third-party maintenance may not be available in as many locations as the manufacturer's service is. A most important feature is that third-party service can cover equipment made by more than one manufacturer. This is a big advantage for those who did not buy the total system from a single manufacturer. On the other hand, remember that it is probably not reasonable to expect that the local parts inventory of the third-party service company will match that of the manufacturers' service organizations.

\section{Third-Party Per-Call Service}

Hourly maintenance service is available from the same third-party sources who supply third-party maintenance contracts. In this case, many of the same rules and limits apply, and contract requests are usually serviced before per-call requests. Note that real bargains exist in some locations where small local third-party service specializes in the repair of only a limited range of items and may not service complete systems. Thirdparty Teletype repair, for example, can be quite cheap. However, your diagnostic skill may again come into play in such cases, since you must be able to identify the system at fault correctly if you are to request service from the proper third-party specialist.

\section{Third-Party Depot Repair}

Similar to manufacturer-based depot repair, you must diagnose the problem and send the defective item (or take it) to a repair depot. In this case, however, you should probably not expect as much from the third party as you would from the manufacturer, with regard to aid in making your diagnosis. It would appear that most third-party depot repair groups are only in the depot repair business. Thus, their inventories may be limited, and you cannot expect them to send you the required item without waiting for your item to arrive and be repaired. Flat-fee repairs are available from these services, and this can result in low-cost repairs, but you must be willing to have your own spare or keep your system down while the repairs are made.

\section{QUESTIONS TO ASK IN SELECTING A SERVICE}

\section{Do You Have a Time-Proven System?}

The manufacturer-based maintenance contract is a real way to extend the limited warranty that comes with a new system. If you have a contract with the manufacturer for service, you can be confident that sooner or later they will get your system to work, 
since they will get tired of coming out to answer service calls. Your fee is not increased by their service failures. Many new designs or configurations have "bugs" in them that no one knows about until after you have accepted delivery and the warranty has run out. The manufacturer tends to be more responsible if you have a continuing maintenance contract. In most cases, a manufacturer-based maintenance contract insures that sooner or later design updates are made. Sometimes these equipment change orders come up 3 or 4 years after purchase! In practice, a hardware contract can be good software insurance, since a frustrated hardware service person may get you a software update to get you off his back!

\section{Where Are You Located?}

Most forms of service on your site require that you pay for travel time. Thus, if you are located in what amounts to a remote geographical location, your choice with regard to the various maintenance options may be quite limited. The differences in travel costs may make your maintenance choice quite simple. Be sure to ask about this before you make a per-call service request or execute a service contract. If you are buying a new system, these are important issues to explore prior to purchase. Proximity of service may make an expensive system cheap if one contemplates several years of operation. Obviously, users located in urban areas with many similar installations have some distinct advantages. This also applies to depot services, since overnight air services are not available everywhere.

\section{What Do Others Do Where You Are?}

For some reason, psychologists tend to isolate themselves and not talk to others about common equipment problems. The laboratory computer is a common and general-purpose instrument. Many others are facing the same problems as you are. What do others in your department do for service? What do people at other institutions in your area do for service? In each case, ask how well satisfied they are with their service. A good vendor in Washington may turn out to be a bad vendor in your town. Above all, beware of service references provided by vendors. Find out for youself.

\section{Who Made Your Hardware and/or Wrote Your Software?}

A third-party service organization is more likely to service hybrid systems in which the system contains items purchased from different sources. You can have a single service source for your total system, even if it includes devices made by several manufacturers, if you go to a third-party organization. If your equipment is old, exotic, or from a defunct company, a third-party service organization may be your only source of service. There is a distinct advantage to having one vendor service a total system, since it does make it more difficult for a maintenance service to shift responsibility to another vendor.

\section{Who Made the Other Hardware in Your}

Department or on Your Campus?

Whereas most manufacturers stick with unit pricing, some third-party service companies provide appropriate adjustments in fees if they are to service complete or multiple systems at the same location. This is true whether or not the systems are made by the same manufacturer. In a similar vein it should be noted that depot repair services may be more attractive if you can get spares on a temporary basis or shared from others at your institution. One might also consider a common spare pool for various users from several institutions in the same geographical area to allow more depot repairing. The development of an in-house maintenance group is another alternative mentioned earlier that may be attractive in some situations. But think twice before you select the latter, since you must consider the cost of parts as well as labor.

\section{What Are the Time Demands on Your Research?}

Many forms of psychological research do not require continuous data collection from individual subjects or sites over a long period of time or on a controlled time schedule. If you can tolerate a significant repair turnaround time, a service contract may not be needed. Computer service people are frequently working with situations that for various reasons require absolutely minimal down-times. In practice, an apparently very prompt response to a request for service to one user may be fairly long for another. Contract holders do get preferred service, but does it really matter to you? Find out from other users what the turn-around repair time is like in your area for a specific vendor. As noted earlier, do not use vendor-supplied data as your sole source of information.

\section{HOW TO PAY FOR IT}

Although there are many approaches to computer maintenance now available to most small computer users, it seems reasonable to suggest that lack of forethought frequently dictates the form of maintenance used. If a serious effort has not been made to explore sources of computer maintenance funds prior to the delivery and installation of a system, it is reasonable to suggest that postdelivery economics direct many users to manufacturer-based per-call service. In the long run, this can be the most expensive route to follow: expensive in the sense that the long-term repair cost may be higher, but also more expensive in the sense that you may lose considerable use time due to more frequent and longer periods of down-time.

Many users purchase their systems with grant funds, but how many include computer maintenance costs in their grant-application budgets? Funding agencies are quite aware of the cost of computer maintenance, and they will frequently pay for it. They are also aware that 
many of those who use small computers are not large batch users. Thus, it is reasonable to suggest that funds to pay for a computer maintenance contract are suitable exchange for payments of large batch computer time charges. Most funding agencies are now sophisticated as to the advantages of small computer applications, and they are quite aware of all of the responsibilities that this involves.

If you are not fortunate enough to have grantsupported maintenance funds, you can also use your system to earn maintenance funds. The power of the contemporary small computer systems now makes it possible to perform many statistical manipulations on small systems that were previously relegated to large batch systems. In some cases, economy of scale no longer holds, and it is possible for you to offer convenient service on your small system at a lower cost. Online real-time data manipulation is just as seductive as on-line real-time data collection. I know of several psychologists who support their systems by selling time to others. This is especially attractive to others if you are at a small institution without a large batch processor. If you are not using the system all the time, sell time or let others use it if they are willing to pay a portion of the maintenance costs.

As noted earlier, communication with other users is very important. It not only makes you wiser, but it may lead to ways of saving money on maintenance. Never assume that other users are well supported and free of financial concerns. Since third-party maintenance companies will service systems differing in manufacturer of origin and are not bound to unit pricing, you might very well be able to build a consortium that can obtain lower maintenance contract costs. In many cases, there is no reason to assume that such consortia be limited to traditional departmental lines. A contract covering systems in both psychology and chemistry, for example, might be both feasible and cheaper than separate contracts covering each department. Also, depot repair may be a satisfactory approach if other systems at your institution can be used for card-swap diagnosis or if several users invest in a joint inventory of spares.

Many psychology departments hesitate to request maintenance funds for their computers when developing their institutional budgets. It is frequently assumed that engineering and computer science departments do their own maintenance and that the administration will not understand why the psychology department cannot do the same thing. Worse yet, a psychology department might choose to hide its maintenance costs or to deny that they exist in a misdirected effort to save a shop man. You may be surprised to find that your engineering and computer science departments do not use in-house maintenance. In learning how other departments maintain their systems, you may also gain a justification for requesting similar maintenance funds for your department from the institution. If the engineers don't fix their own, how can you expect the psychologists to do it?

In conclusion, an important theme of this paper should be noted. The contemporary small computer user is frequently misperceived. Those who do not have small computer systems frequently assume that small computer users are electronic repair wizards with little or no financial concerns. This may have been true 20 years ago, but it no longer holds as a general rule. More frequently, the opposite is true. The small com puter user has few repair skills and a financial burden induced by the purchase of computer equipment. Given these two characteristics, communication among small computer users is in order if there is to be an economical use of the various forms of computer main tenance now available to most users. 